\title{
Thermochemistry and photochemistry of spiroketals derived from indan-2-one: Stepwise processes versus coarctate fragmentations
}

\author{
Götz Bucher ${ }^{*} 1,2$, Gernot Heitmann ${ }^{3}$ and Rainer Herges ${ }^{\star 3}$
}

\section{Full Research Paper}

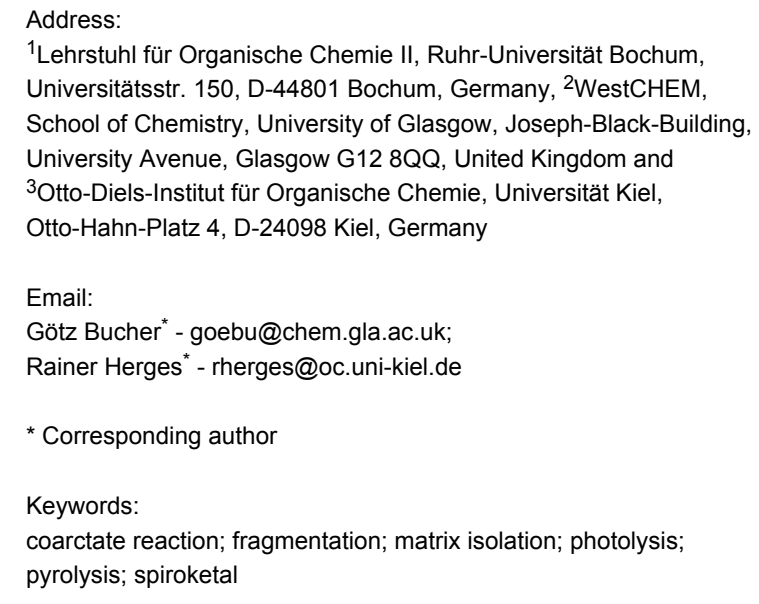

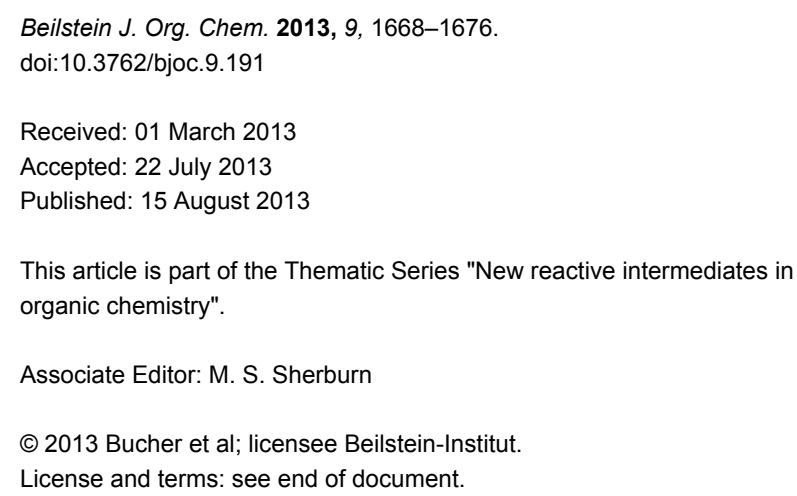

\begin{abstract}
Coarctate reactions are defined as reactions that include atoms at which two bonds are made and two bonds are broken simultaneously. In the pursuit of the discovery of new coarctate reactions we investigate the fragmentation reactions of cyclic ketals. Three ketals with different ring sizes derived from indan-2-one were decomposed by photolysis and pyrolysis. Particularly clean is the photolysis of the indan-2-one ketal $\mathbf{1}$, which gives $o$-quinodimethane, carbon dioxide and ethylene. The mechanism formally corresponds to a photochemically allowed coarctate fragmentation. Pyrolysis of the five-ring ketal yields a number of products. This is in agreement with the fact that coarctate fragmentation observed upon irradiation would be thermochemically forbidden, although this exclusion principle does not hold for chelotropic reactions. In contrast, fragmentation of the seven-ring ketal $\mathbf{3}$ is thermochemically allowed and photochemically forbidden. Upon pyrolysis of $\mathbf{3}$ several products were isolated that could be explained by a coarctate fragmentation. However, the reaction is less clean and stepwise mechanisms may compete.
\end{abstract}

\section{Introduction}

Pericyclic reactions, according to the original definition, are characterized by a cyclic array of bond making and bond breaking [1-3]. At each atom, involved in the reaction, one bond is made and one bond is broken. However, there are a number of reactions that include a linear system of atoms, or at least one atom, at which two bonds are made and two bonds broken sim- 
ultaneously. Nevertheless, their transition states exhibit a cyclic overlap of basis orbitals. The orbital basis can be derived from the orbital basis of pericyclic transition states by constriction (coarctation, Figure 1). Hence, these reactions have been coined "coarctate" reactions $[4,5]$.
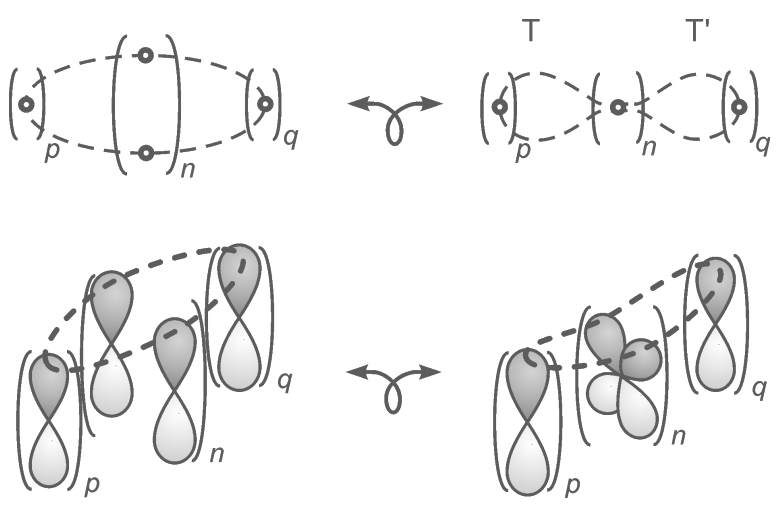

Figure 1: Formal, topological approach to derive coarctate reactions from pericyclic reactions; $p, q$ : number of atoms or basis orbitals in the terminator groups T and T'; $n$ : number of orthogonal pairs of basis orbitals in the transition state of coarctate reactions.

Similar to pericyclic reactions [6], rules were derived to predict their stereochemistry, and whether they would be thermochemically or photochemically allowed. The atom (or the linear system of atoms) at which two bonds are made and broken, each contribute two basis orbitals to the transition state (Figure 1, bottom, right). A cyclic array of orbitals is attained if the linear system of orbital overlap at each end is bound by terminating groups, e.g. a lone pair, or two atoms to form a three-ring, or four atoms to a five-ring, etc. Similar to pericyclic reactions, thermochemical coarctate reactions proceed via Hückel transition states, if the number of delocalized electrons in the transition state is $4 n+2$, and they exhibit Möbius transition states with $4 n$ electrons. If in a formal, topological transformation a closed ribbon is transformed into a coarctate band, the two loops T and T' that are formed are coplanar. The analogous transformation of a Möbius ribbon leads to a band whose loops are orthogonal with respect to each other (Figure 2).

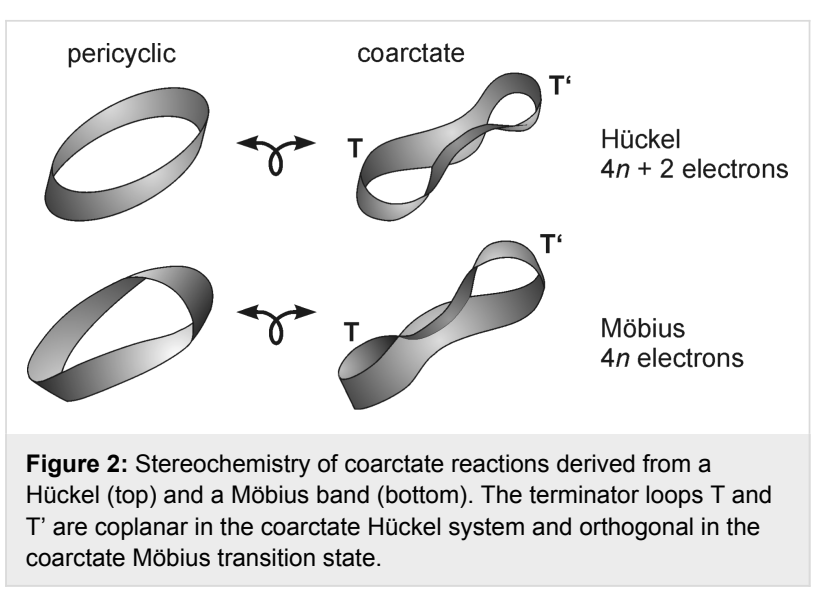

Following the above principle we developed a number of novel coarctate reactions [7-11], several of which provide synthetic access to a broad range of heterocycles [12-21]. Synthetically probably less useful, but suitable to check the coarctate stereochemical rules, is a peculiar fragmentation reaction that we discovered 15 years ago (Scheme 1) [9,10].

The reaction proceeds spontaneously at temperatures below $-80{ }^{\circ} \mathrm{C}$. Quantum chemical calculations of the parent reaction predict an activation barrier of $11.3 \mathrm{kcal} / \mathrm{mol}$ and a concerted mechanism. This is in agreement with the stereochemical rule that a coarctate reaction with eight $(4 n)$ electrons should proceed via a Möbius transition state, with the two terminating groups orthogonal with respect to each other. The orthogonal arrangement is provided by the spiro connection of the threeand the five-membered rings. Following these rules, a Möbius type coarctate fragmentation with two five-ring terminators (10 electrons) should proceed as a photochemical reaction, and a corresponding fragmentation with a seven- and a five-ring (12 electrons) should be thermochemically activated (Scheme 2) [22].

To test the above hypothesis, we now investigate the thermochemistry and the photochemistry of the ketals $\mathbf{1}$ and $\mathbf{3}$, derived from indan-2-one and ethylene glycol, and cis-2-butene-1,4-diol (Scheme 3). The ketal 2, derived from 1,3-propanediol, was chosen as a reference system that cannot undergo a coarctate fragmentation.

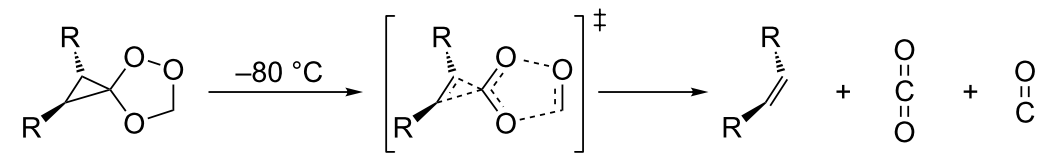




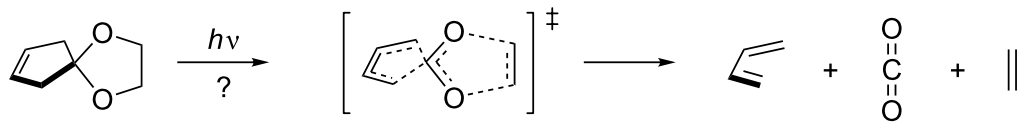

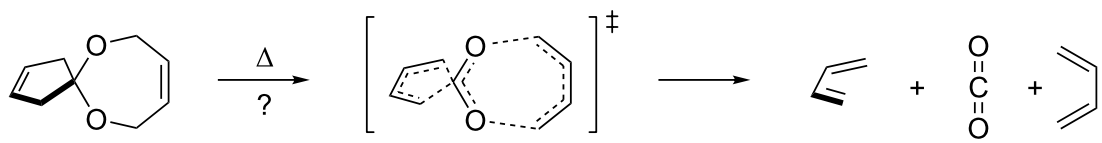

Scheme 2: Photochemically and thermally allowed coarctate fragmentations of spiroketals.

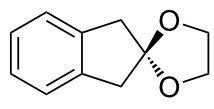

1<smiles>c1ccc2c(c1)CC1(C2)OCCCO1</smiles>

2<smiles>C1=COC2(Cc3ccccc3C2)OC1</smiles>

3

Scheme 3: Precursors used in this study.

\section{Results}

Photolysis and pyrolysis of the ketals. Photolysis $\left(\lambda_{\mathrm{exc}}=\right.$ $254 \mathrm{~nm}, \mathrm{Hg}$ low-pressure lamp) of indan-2-one ethylene ketal (1), matrix-isolated in $\mathrm{Ar}$ at $10 \mathrm{~K}$, leads to the formation of $\mathrm{CO}_{2}$ $\left(\mathrm{vs}, v=2342.1 \mathrm{~cm}^{-1}\right), o$-xylylene $(\mathbf{X Y}, v=1550.4,1470.8$, $\left.1467.4,873.1,776.2,738.7 \mathrm{~cm}^{-1}\right)$ [23], ethylene (ET, $\left.v=1438.1,953.8 \mathrm{~cm}^{-1}\right)$ and indan-2-one (IN, $v=1761.0$ $\mathrm{cm}^{-1}$ ). Some weak product bands could not be assigned. A difference IR spectrum (product bands at a very early stage of the photolysis minus precursor bands) is given in Figure 3.

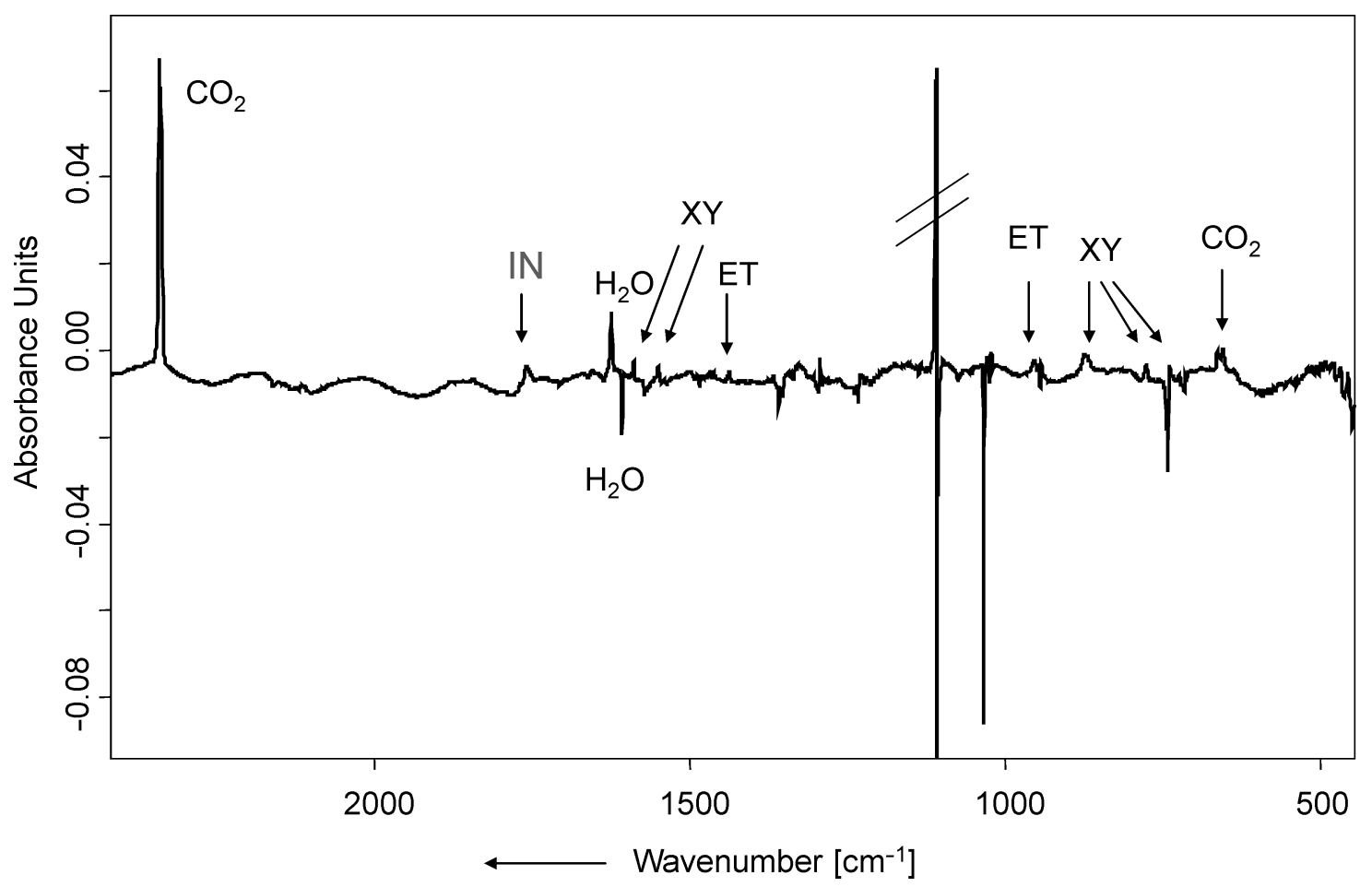

Figure 3: Difference infrared spectrum, showing the changes in the IR spectrum after photolysis $\left(\lambda_{\text {exc }}=254 \mathrm{~nm}, 20 \mathrm{~min}\right)$ of 1 in Ar matrix. Except for the water band, all IR bands pointing downwards belong to 1 . Product bands pointing upwards are labelled according to their assignment $(\mathbf{X Y}=$ $o$-xylylene, ET = ethylene, IN = indan-2-one). The intense band pointing upwards at $1109 \mathrm{~cm}^{-1}$ is an artefact due to a subtraction error of a very intense precursor band. 
Figure 3 clearly shows that at least at this early stage of photolysis, practically no $\mathrm{CO}\left(v=2138.4 \mathrm{~cm}^{-1}\right)$ is formed. At a later stage of photolysis ( $20 \mathrm{~h}, \lambda=254 \mathrm{~nm}), \mathrm{CO}$ is also detected, and the relative integrals of the $\mathrm{CO}_{2}$ and $\mathrm{CO}$ bands yield an estimated ratio of $\mathrm{CO}_{2}$ and $\mathrm{CO}$ of 2.5:1. It is noted, however, that the formation of $\mathrm{CO}$ may well be due to photolysis of $\mathrm{CO}_{2}$ due to hard UV radiation $(\lambda=185 \mathrm{~nm})$ also emitted by the $\mathrm{Hg}$ lowpressure lamp used [24].

In contrast to the very clean photochemistry of $\mathbf{1}$, flash vacuum pyrolysis FVP $\left(T=870^{\circ} \mathrm{C}\right)$ of $\mathbf{1}$, followed by trapping of the reaction products in solid argon, yielded a variety of products whose identity could only partially be elucidated. The ratio of $\mathrm{CO}_{2} / \mathrm{CO}$ being formed in the pyrolysis reaction was different from the photochemical decomposition of $\mathbf{1}$. Based on the integrals of the $\mathrm{CO}_{2}$ and $\mathrm{CO}$ bands, it can be estimated as 1:27. Figure 4 shows an infrared spectrum of the pyrolysis products.

The organic products include formaldehyde (FA), acetaldehyde (AA), ethene (ET), o-xylylene (XY), benzocyclobutene (BC), styrene (ST), and indan-2-one (IN). Some peaks could not be assigned. The assignment of the pyrolysis products is based on a comparison with literature data (XY) [21], as well as reference spectra of authentic samples (ET, BC, IN, AA, FA, ST). By calibrating IR band integrals to calculated (B3LYP/6$31 \mathrm{G}(\mathrm{d}, \mathrm{p})$ ) IR band intensities of selected bands, a crude measure of product ratios could be obtained. Relative to
$\left[\mathrm{CO}_{2}\right]=1.0$, the concentrations of the other pyrolysis products are as follows: $[\mathrm{CO}]=27.2,[\mathbf{I N}]=3.8,[\mathbf{E T}]=15.9$, $[\mathbf{B C}]=11.4,[\mathbf{X Y}]=1.3,[\mathbf{A A}]=3.9[25]$. Formaldehyde is formed as a minor product only.

The photochemistry of ketals $\mathbf{2}$ and $\mathbf{3}$ was investigated as well by matrix isolation spectroscopy. Unfortunately no product could be unambiguously identified. The FVP of 2 yielded the product spectrum shown in Figure 5. Again, both carbon monoxide and carbon dioxide were formed along with the organic products. Carbon monoxide was formed in large excess over carbon dioxide $\left(\mathrm{CO} / \mathrm{CO}_{2}=13.5: 1\right)$. Organic products include mostly FA, ET, and IN, as well as BC and XY, but many peaks have to remain unassigned. Propene was not formed. Compared to the FVP of $\mathbf{1}$, the FVP of $\mathbf{2}$ yields significantly increased amounts of 2-indanone and formaldehyde. Relative to $\left[\mathrm{CO}_{2}\right]=1.0$, the concentrations of the other pyrolysis products are as follows: $[\mathrm{CO}]=13.5,[\mathbf{I N}]=9.1$, $[\mathbf{E T}]=15.4,[\mathbf{B C}]=19.4,[\mathbf{X Y}]=1.2,[\mathbf{F A}]=12.2$.

Flash vacuum pyrolysis of indan-2-one cis-2-butene-1,4-diol ketal (3) again gave rise to a complex mixture of products (Figure 6). Among them, the two conformers of 1,3-butadiene (tBD and CBD) could be assigned based on a comparison with literature data [26]. Further products include $o$-xylylene (XY), benzocyclobutene (BC), indan-2-one (IN), and formaldehyde (FA). Again, a number of IR peaks have to remain unassigned.

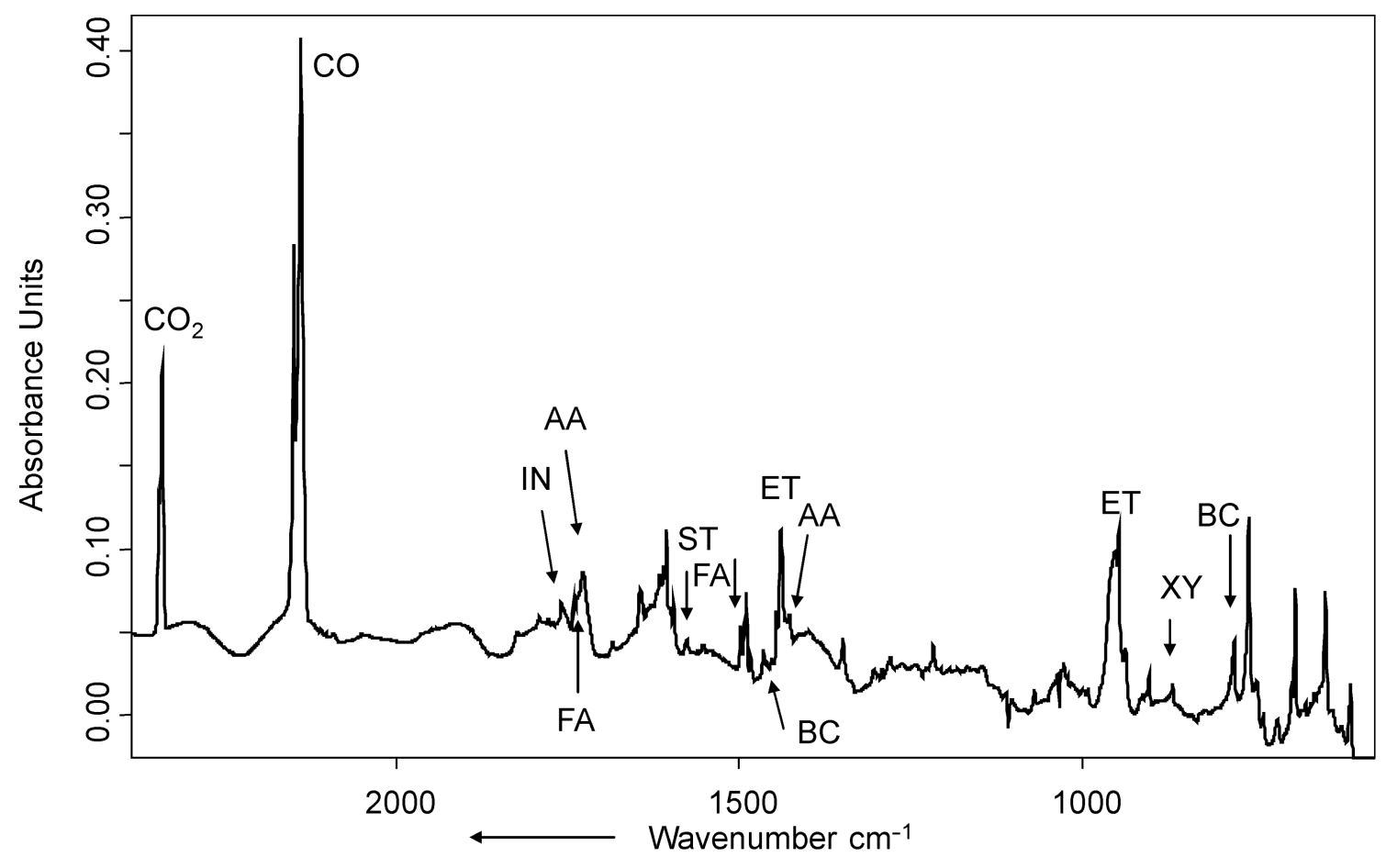

Figure 4: Infrared spectrum obtained upon FVP of 1 at $T=1143 \mathrm{~K}$ and trapping the pyrolysate in solid argon at $T=10 \mathrm{~K}$. 


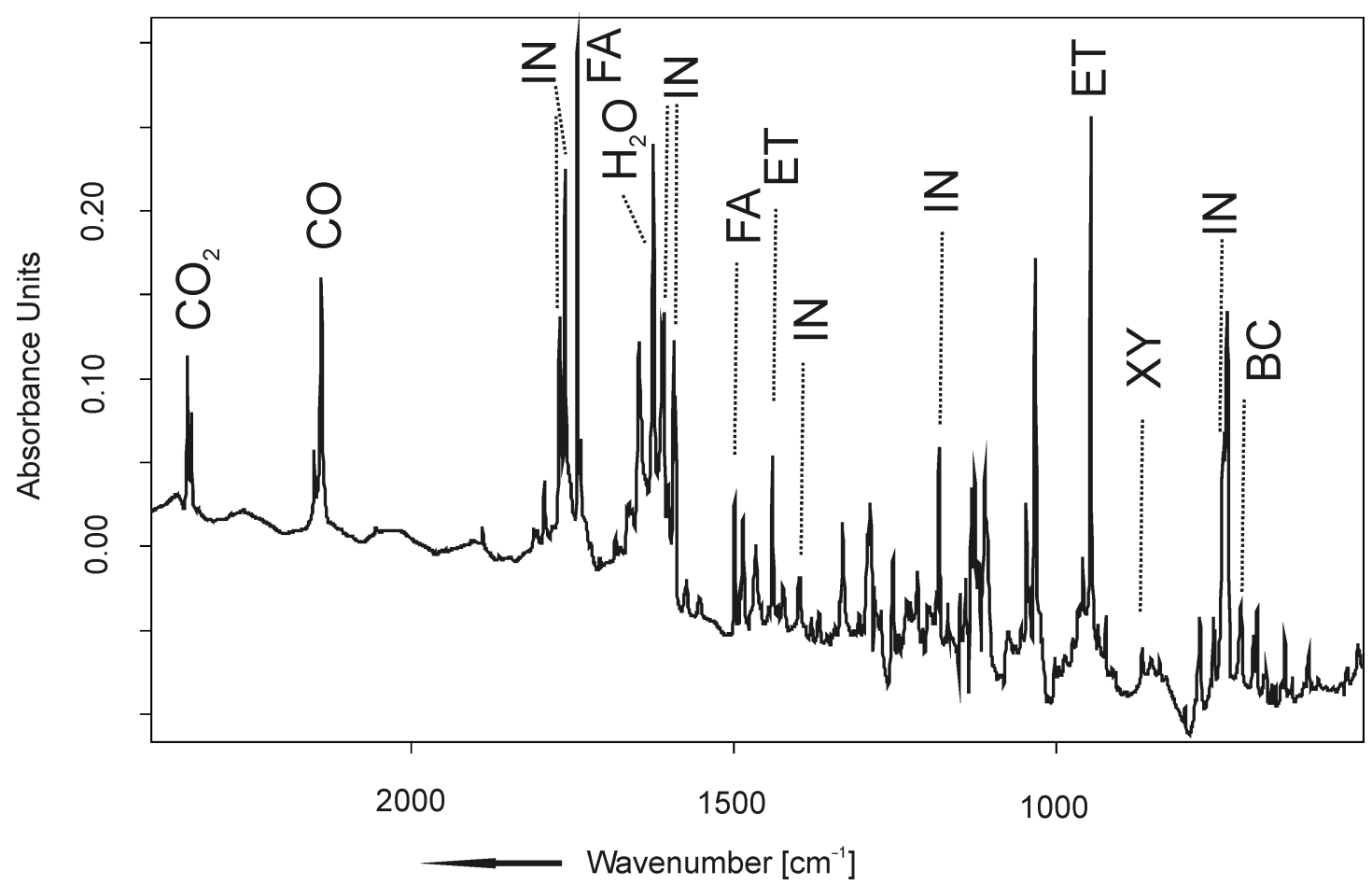

Figure 5: Infrared spectrum obtained upon FVP of 2 at $T=963 \mathrm{~K}$ and trapping the pyrolysate in solid argon at $T=10 \mathrm{~K}$.

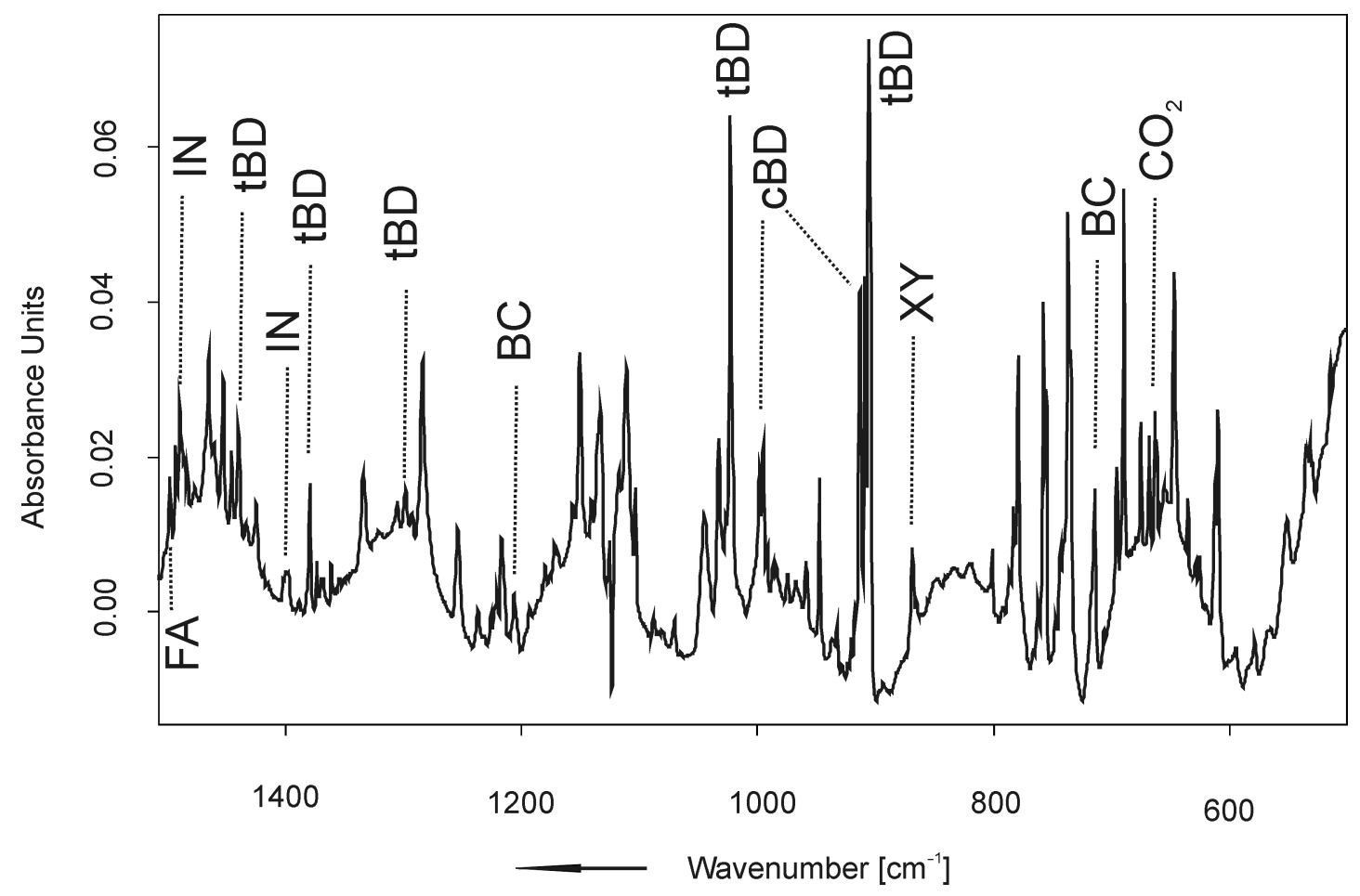

Figure 6: Infrared spectrum obtained upon FVP of 3 at $T=1043 \mathrm{~K}$ and trapping the pyrolysate in solid argon at $T=10 \mathrm{~K}$. 
$\mathrm{CO}_{2}$ and $\mathrm{CO}$ are formed in a ratio of 1:2.6 in this pyrolysis reaction. Relative to $\left[\mathrm{CO}_{2}\right]=1.0$, the concentrations of the pyrolysis products are as follows: $[\mathrm{CO}]=2.6,[\mathbf{I N}]=1.0,[\mathbf{t B D}]=$ $7.4,[\mathbf{c B D}]=1.5,[\mathbf{B C}]=6.3,[\mathrm{XY}]=0.4$.

\section{Discussion}

Flash vacuum pyrolysis of $\mathbf{1}$ yields a complex mixture, which contains a variety of fragmentation products derived from both sides of the spiroketal linkage. The relative ratio of carbon dioxide and carbon monoxide being formed $\left(\mathrm{CO}_{2} / \mathrm{CO}=1: 27\right)$ indicates that a coarctate fragmentation of $\mathbf{1}$ can play a minor role only, if any. The composition of the product mixture is best rationalized by a series of stepwise processes, which starts with either a $\mathrm{C}-\mathrm{C}$ cleavage (pathway $\mathrm{A}$, more favourable) or a $\mathrm{C}-\mathrm{O}$ cleavage (pathways B or $\mathrm{C}$, less favourable). In principle, a chelotropic elimination of 1,3-dioxol-2-ylidene is also conceivable (pathway D). Scheme 4 shows a possible mechanistic scenario. While it is questionable whether the biradical intermediates shown in Scheme 4 are in fact true minima or not, we note that they will be exceedingly short-lived at $T=1143 \mathrm{~K}$ in any event.

As the $\mathrm{C}-\mathrm{C}$ bond being broken in mechanism $\mathrm{A}$ is significantly weaker than the $\mathrm{C}-\mathrm{O}$ bonds that need to be cleaved in mechanisms $\mathrm{B}$ and $\mathrm{C}$, pathway $\mathrm{A}$ is expected to be the most facile decay mechanism for $\mathbf{1}$. The primarily formed benzyldialkoxymethyl biradical 4 should undergo a very facile ring-opening reaction to yield an ester biradical 7, which can either cleave into ethylene, carbon dioxide and $o$-xylylene (XY), or eliminate acetaldehyde (AA) to yield an acyl-benzyl diradical 9 [27]. The latter can then either undergo ring closure to form indan-2-one (IN), or decarbonylate to give $o$-xylylene (XY). The equilibrium of $\mathbf{X Y}$ and benzocyclobutene (BC) is established in the literature [28], as well as the formation of styrene ST from BC [29]. An alternative mechanism, the chelotropic elimination of 1,3-dioxolan-2-ylidene is not likely. This carbene has been generated from a norbornadiene spiro ketal, and it cleanly fragmented into $\mathrm{CO}_{2}$ and ethylene [30]. Theoretical calculations support the low barrier for fragmentation [31]. We explain the different reaction behaviour of our spiroketal 1 by the fact that two energetically unfavourable products would have to be formed (a quinodimethane and a carbene), whereas the fragmentation of the norbornadiene ketal gives benzene and a carbene. The mechanism for the thermal decomposition of $\mathbf{2}$ is likely to be similar. The high yield of formaldehyde in the pyrolysis of $\mathbf{2}$ is readily explained by the fact that the ester biradical $\mathbf{1 3}$ formed can lose one equivalent of ethene and formaldehyde to yield the acyl-benzyl type biradical 15 (Scheme 5).

In the FVP of $\mathbf{1}$ and $\mathbf{2}, \mathrm{CO}$ is formed in large excess over $\mathrm{CO}_{2}$. This excess is far less pronounced in the FVP of $\mathbf{3}$. This could possibly indicate that a coarctate fragmentation of $\mathbf{3}$ (which would be a concerted version of pathway $\mathrm{C}$ in Scheme 3) could

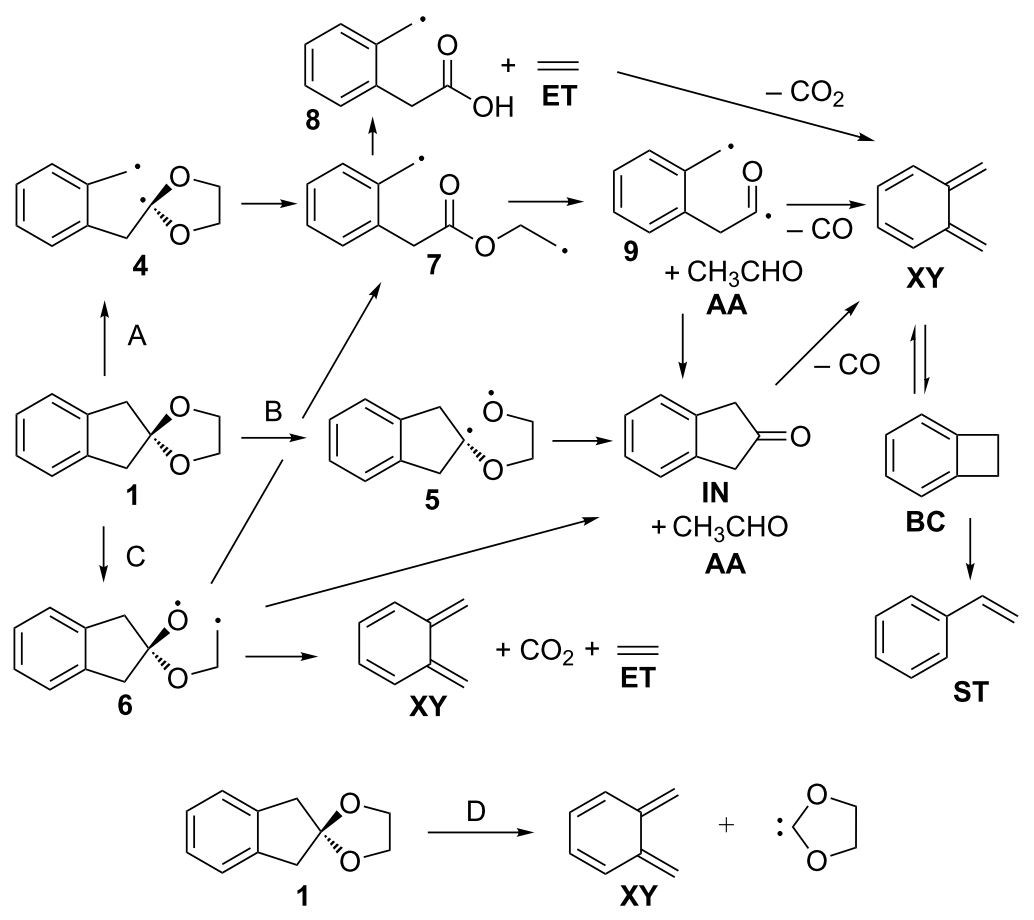

Scheme 4: Possible fragmentation pathways in the FVP of 1. 


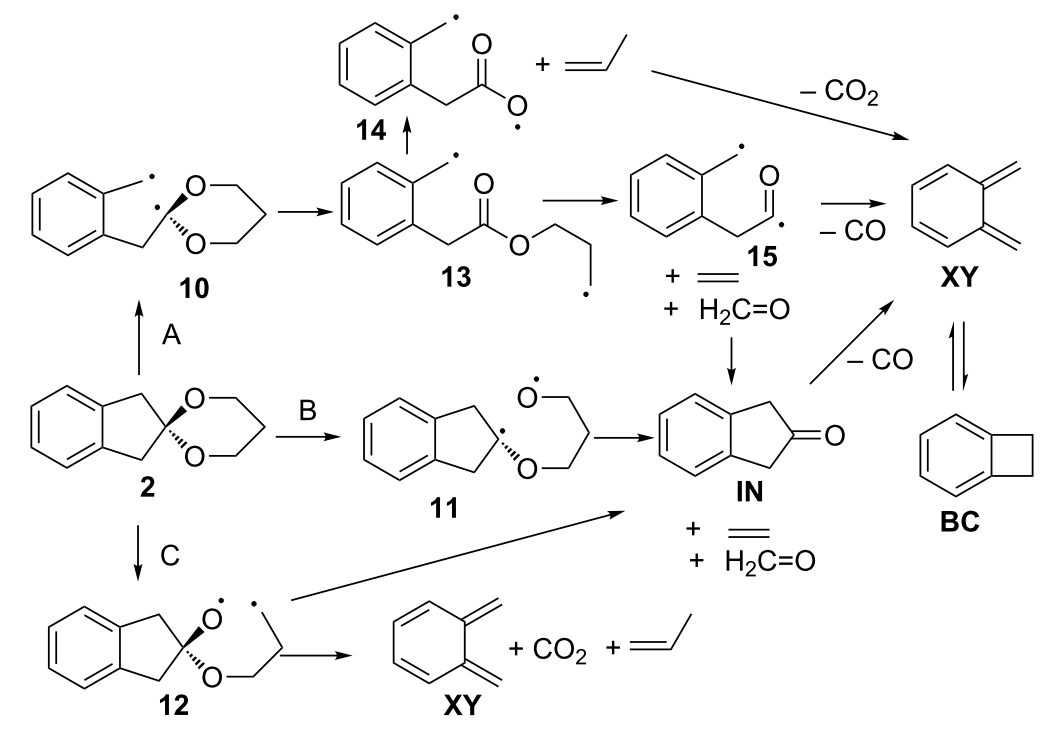

Scheme 5: Possible fragmentation pathways in the FVP of 2.

possibly also contribute to the product distribution (Scheme 6). A chelotropic reaction forming 4,7-dihydro-1,3-dioxepine-2ylidene as discussed in the fragmentation of 5-ring spiroketal 1 cannot be excluded. It is known that the sulfur analogue 4,7-dihydro-1,3-dithiepine-2-yldidene cleanly fragments into carbon disulfide and butadiene [32]; however, 4,7-dihydro-1,3dioxepine-2-ylidene does not give carbon dioxide and butadiene [33].

\section{Conclusion}

In agreement with predictions, spiroketals derived from indan2-one undergo photochemical coarctate fragmentation, if both terminators are 5-membered rings, and thermal coarctate fragmentation, if both a 5-ring and a 7-ring terminator are present. In the latter case, the experimental evidence suggests that the thermal coarctate fragmentation competes with stepwise processes.

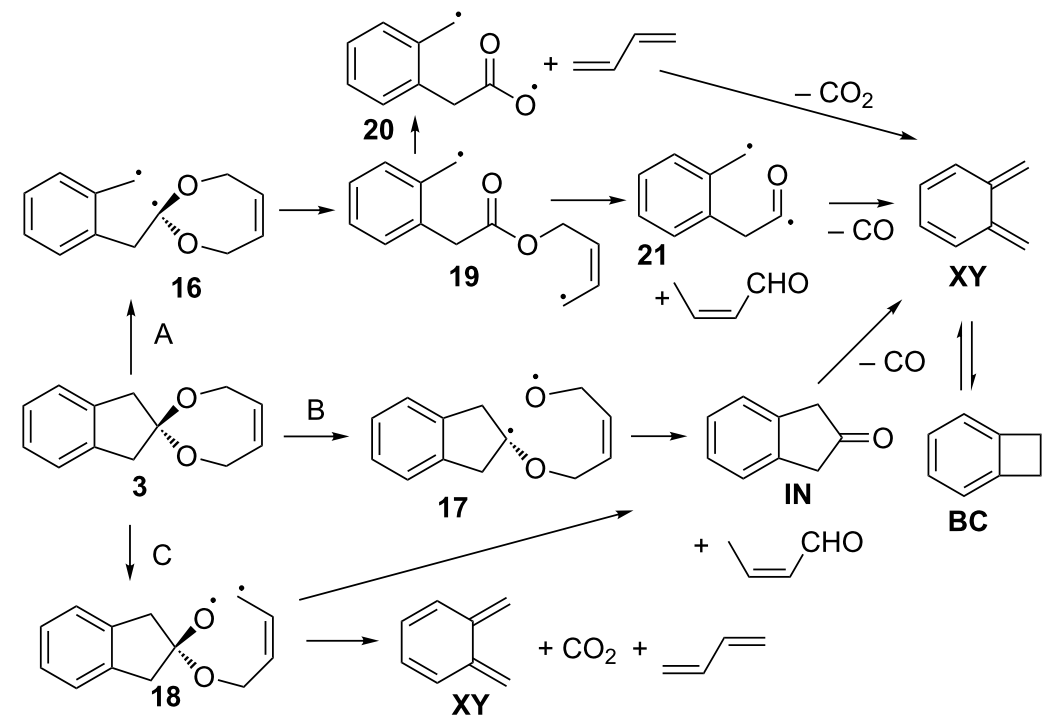




\section{Experimental}

General: Matrix-isolation experiments were performed using standard matrix-isolation techniques [34]. For sample deposition, the slow-spray-on technique was used. Sample temperatures for deposition were ambient temperature (1), ca. $40{ }^{\circ} \mathrm{C} \mathrm{(2)}$, and ca. $60{ }^{\circ} \mathrm{C} \mathrm{(3)}$. The argon used was of $99.999 \%$ purity. In pyrolysis experiments, the length of the pyrolysis zone was ca. $5 \mathrm{~cm}$. Reference IR spectra of benzocyclobutene, styrene, indan-2-one, acetaldehyde, formaldehyde, ethene and propene in Ar matrices were independently measured. IR spectra were recorded with a resolution of $0.5 \mathrm{~cm}^{-1}$. The outer matrix window used for photolysis was from Suprasil quartz specified for transmission down to $\lambda=190 \mathrm{~nm}$.

Ketal 1 was synthesized according to a published procedure [35]. Ketals $\mathbf{2}$ and $\mathbf{3}$ were prepared analogously, starting from indan-2-one and propane-1,3-diol and cis-2-butene-1,4-diol, respectively.

Indan-2-one ethylene ketal (1): IR (Ar, $10 \mathrm{~K}) \mathrm{v}: 3109.2$ (vw), 3084.4 (vw), 3057.7 (vw), 3034.8 (w), $2993.3(\mathrm{w}), 2989.6(\mathrm{w})$, 2962.3 (w), 2928.9 (vw), 2898.5 (w), 2894.8 (w), 2878.1 (w), $2834.1(\mathrm{vw}), 1598.6(\mathrm{vw}), 1485.5(\mathrm{~m}), 1472.5(\mathrm{vw}), 1465.1$ (vw), 1421.1 (vw), $1342.4(\mathrm{vw}), 1331.9(\mathrm{~m}), 1305.9(\mathrm{vw})$, 1292.9 (s), $1233.4(\mathrm{~m}), 1222.9(\mathrm{w}), 1200.0(\mathrm{w}), 1160.9(\mathrm{vw})$, $1136.8(\mathrm{~m}), 1110.3(\mathrm{vs}), 1074.2(\mathrm{w}), 1051.9(\mathrm{vw}), 1033.3(\mathrm{~s})$, $1027.8(\mathrm{~m}), 1019.7(\mathrm{w}), 944.4(\mathrm{w}), 867.0(\mathrm{vw}), 785.9(\mathrm{vw})$, 741.7 (s), $715.7(\mathrm{~m}), 597.7(\mathrm{vw}), 590.5(\mathrm{vw}), 536.8(\mathrm{vw}) \mathrm{cm}^{-1}$.

Synthesis of 2: Indan-2-one propane-1,3-diol ketal (2) was prepared as described for the synthesis of $\mathbf{1}$, with the exception of the use of toluene rather than benzene as solvent. Indan-2one (2.0 g, $0.015 \mathrm{~mol})$ and 1,3-propanediol $(1.4 \mathrm{~g}, 0.018 \mathrm{~mol})$ were heated under reflux in $100 \mathrm{~mL}$ toluene together with $20 \mathrm{mg} p$-toluenesulfonic acid. The mixture was heated under reflux for $12 \mathrm{~h}$, during which time the water formed was distilled off as an azeotrope with toluene. The toluenic solution was then washed twice with aq $\mathrm{NaHCO}_{3}$ and once with water. After drying over anhydrous $\mathrm{Na}_{2} \mathrm{SO}_{4}$, the toluene was removed on a rotary evaporator. Purification of the crude product thus obtained was achieved by distillation in high vacuum. Yield $1.2 \mathrm{~g}(42 \%)$ after distillation. bp $93-97{ }^{\circ} \mathrm{C}$ (0.01 mbar); mp $44{ }^{\circ} \mathrm{C} ;{ }^{1} \mathrm{H} \mathrm{NMR}\left(\mathrm{CDCl}_{3}, 400 \mathrm{MHz}\right) \delta 7.14(\mathrm{~m}, 4 \mathrm{H}), 3.97$ (t, $J=$ $5.5 \mathrm{~Hz}, 4 \mathrm{H}), 3.28(\mathrm{~s}, 4 \mathrm{H}), 1.78(\mathrm{~m}, 2 \mathrm{H}) \mathrm{ppm} ;{ }^{13} \mathrm{C} \mathrm{NMR}$ $\left(\mathrm{CDCl}_{3}, 100 \mathrm{MHz}\right) \delta 139.68,126.65,124.71,109.23,61.52$, 42.54, 25.56 ppm; IR (Ar, $10 \mathrm{~K})$ v: 3111.7 (vw), 3084.8 (vw), 3076.7 (vw), 3060.8 (vw), $3050.1(\mathrm{w}), 3039.8(\mathrm{w}), 3035.7(\mathrm{w})$, 2993.7 (w), 2983.8 (m), 2980.1 (m), 2972.7 (m), 2962.7 (m), $2949.8(\mathrm{~m}), 2943.1(\mathrm{~m}), 2930.7(\mathrm{~m}), 2908.2(\mathrm{w}), 2899.4(\mathrm{w})$, $2891.9(\mathrm{w}), 2884.6(\mathrm{~m}), 2879.0(\mathrm{~m}), 2876.1(\mathrm{~m}), 2858.9(\mathrm{~m})$, $2849.9(\mathrm{w}), 2727.6$ (vw), 2717.7 (vw), 1620.4 (w), 1612.1 (vw), $1592.5(\mathrm{vw}), 1572.9(\mathrm{vw}), 1488.3(\mathrm{~m}), 1477.1(\mathrm{w}), 1464.8(\mathrm{w})$, $1433.4(\mathrm{w}), 1425.9(\mathrm{w}), 1381.5(\mathrm{w}), 1369.9(\mathrm{w}), 1333.7(\mathrm{~m})$, 1305.7 (vw), 1298.5 (w), 1284.5 (vs), $1254.1(\mathrm{~m}), 1237.4(\mathrm{w})$, $1215.2(\mathrm{w}), 1170.3(\mathrm{vw}), 1150.9$ (vs), 1135.6 (vs), 1133.0 (vs), $1117.7(\mathrm{~s}), 1111.0(\mathrm{vs}), 1081.2(\mathrm{w}), 1045.9(\mathrm{~s}), 1032.9(\mathrm{~s})$, $1024.0(\mathrm{~m}), 966.3(\mathrm{w}), 937.6(\mathrm{w}), 868.8(\mathrm{w}), 734.8(\mathrm{~s}), 678.9$ (vw), 607.2 (vw), $594.3(\mathrm{vw}), 555.4(\mathrm{vw}) \mathrm{cm}^{-1}$; EIMS m/z: $\mathrm{M}^{+}$ 190 (100), 176, 161, 132 (68), 104 (80), 91, 77, 51; Anal. calcd for $\mathrm{C}_{12} \mathrm{H}_{14} \mathrm{O}_{2}$ : C, 75.8; $\mathrm{H}, 7.4$; found: $\mathrm{C}, 75.3 ; \mathrm{H}, 7.2$.

Indan-2-one cis-2-butene-1,4-diol ketal (3) was prepared analogously. Due to the limited thermal stability of $\mathbf{3}$, benzene had to be used as solvent, and the product could not be distilled. Instead, a sample of the solid dark brown crude product was purified by sublimation in ultra-high vacuum $\left(10^{-6} \mathrm{mbar}\right)$, using matrix-isolation equipment. Colourless crystals, mp $78{ }^{\circ} \mathrm{C}$; ${ }^{1} \mathrm{H} \mathrm{NMR}\left(\mathrm{CDCl}_{3}, 400 \mathrm{MHz}\right) \delta 7.16(\mathrm{~m}, 4 \mathrm{H}), 5.73(\mathrm{t}, J=1.5 \mathrm{~Hz}$, $2 \mathrm{H}), 4.31$ (d, $J=1.5 \mathrm{~Hz}, 4 \mathrm{H}), 3.25$ (s, 4H) ppm; ${ }^{13} \mathrm{C}$ NMR $\left(\mathrm{CDCl}_{3}, 100 \mathrm{MHz}\right) \delta 139.84,129.53,126.63,124.64,113.31$, 62.93, 44.07 ppm; IR (Ar, $10 \mathrm{~K})$ v: $3078.6(\mathrm{vw}), 3058.5(\mathrm{vw})$, 3046.1 (w), 2986.4 (vw), 2966.8 (vw), 2952.9 (w), 2949.1 (w), $2945.8(\mathrm{w}), 2926.2(\mathrm{w}), 2920.9(\mathrm{w}), 2912.3(\mathrm{w}), 2908.0(\mathrm{w})$, $2865.0(\mathrm{w}), 2838.8(\mathrm{vw}), 2718.3(\mathrm{vw}), 1622.9(\mathrm{w}), 1612.3(\mathrm{vw})$, $1607.9(\mathrm{vw}), 1592.9(\mathrm{vw}), 1589.4(\mathrm{vw}), 1573.0(\mathrm{vw}), 1487.9$ (m), $1465.8(\mathrm{w}), 1449.2(\mathrm{w}), 1425.2(\mathrm{w}), 1390.2(\mathrm{w}), 1363.3$ (w), $1330.3(\mathrm{~m}), 1306.4(\mathrm{w}), 1284.9(\mathrm{~s}), 1227.6(\mathrm{~m}), 1220.9$ (w), $1201.7(\mathrm{~m}), 1167.6(\mathrm{w}), 1155.8(\mathrm{w}), 1123.8(\mathrm{vs}), 1115.4$ (w), $1102.2(\mathrm{vw}), 1090.2(\mathrm{~s}), 1078.3(\mathrm{~m}), 1044.6(\mathrm{~s}), 1026.9$ (m), $1009.9(\mathrm{~m}), 951.9(\mathrm{vw}), 946.6(\mathrm{vw}), 920.8(\mathrm{vw}), 879.4$ (vw), $872.8(\mathrm{vw}), 817.4(\mathrm{vw}), 732.5(\mathrm{~s}), 684.8(\mathrm{vw}), 667.8(\mathrm{vw})$, $641.8(\mathrm{~m}), 619.4(\mathrm{~m}), 617.4(\mathrm{~m}), 595.8(\mathrm{w}), 559.1(\mathrm{vw}), 527.5$ (vw) $\mathrm{cm}^{-1}$; EIMS m/z: $\mathrm{M}^{+} 202$ (55), 176, 161, 149, 148, 147, 132, 104 (100), 91, 78, 54 (95), 51, 39; Anal. calcd for for $\mathrm{C}_{13} \mathrm{H}_{14} \mathrm{O}_{2}$ : C, 77.2; H, 7.0; found: C, 77.5; H, 7.0; HRMS-ESI $(\mathrm{m} / \mathrm{z})$ : $[\mathrm{M}]^{+}$calcd for $\mathrm{C}_{13} \mathrm{H}_{14} \mathrm{O}_{2} \mathrm{Na}, 225.0898$; found, 225.0891 .

\section{Acknowledgements}

Financial support by the Deutsche Forschungsgemeinschaft and EPSRC (Glasgow Centre for Physical Organic Chemistry as part of WestCHEM) is gratefully acknowledged. The authors thank W. Sander for access to matrix isolation equipment.

\section{References}

1. Woodward, R. B.; Hoffmann, R. Angew. Chem. 1969, 81, 797-869. doi:10.1002/ange.19690812102

Angew. Chem., Int. Ed. Engl. 1969, 8, 781-853. doi:10.1002/anie.196907811

2. Zimmerman, H. E. Acc. Chem. Res. 1971, 4, 272-280. doi:10.1021/ar50044a002 
3. Dewar, M. J. S. Angew. Chem. 1971, 83, 859-875. doi:10.1002/ange.19710832202

Angew. Chem., Int. Ed. Engl. 1971, 10, 761-776. doi:10.1002/anie.197107611

4. Herges, R. Angew. Chem. 1994, 106, 261-283. doi:10.1002/ange.19941060304

Angew. Chem., Int. Ed. Engl. 1994, 33, 255-276. doi:10.1002/anie.199402551

5. Herges, R. J. Chem. Inf. Comput. Sci. 1994, 34, 91-102. doi:10.1021/ci00017a011

6. Unruh, G. R.; Birney, D. M. J. Am. Chem. Soc. 2003, 125, 8529-8533. doi:10.1021/ja0353661

7. Banert, K.; Grimme, S.; Herges, R.; Heß, K.; Köhler, F.; Mück-Lichtenfeld, C.; Würthwein, E.-U. Chem.-Eur. J. 2006, 12, 7467-7481. doi:10.1002/chem.200600318

8. Banert, K.; Köhler, F.; Melzer, A.; Scharf, I.; Rheinwald, G.; Rüffer, T.; Lang, H.; Herges, R.; Heß, K.; Ghavtadze, N.; Würthwein, E.-U. Chem.-Eur. J. 2011, 17, 10071-10080. doi:10.1002/chem.201101220

9. Herges, R.; Geuenich, D.; Bucher, G.; Tönshoff, C. Chem.-Eur. J. 2000, 6, 1224-1228. doi:10.1002/(SICI)1521-3765(20000403)6:7<1224::AID-CHEM1224>3. 3.CO;2-8

10. Berger, C.; Bresler, C.; Dilger, U.; Geuenich, D.; Herges, R.; Röttele, H.; Schröder, G. Angew. Chem. 1998, 110, 1951-1953. doi:10.1002/(SICI)1521-3757(19980703)110:13/14<1951::AID-ANGE1 951>3.0.CO;2-B

Angew. Chem., Int. Ed. 1998, 37, 1850-1853. doi:10.1002/(SICI)1521-3773(19980803)37:13/14<1850::AID-ANIE185 0>3.0.CO;2-B

11. Berger, C.; Dieterich, S.; Dilger, U.; Geuenich, D.; Helios, H.; Herges, R.; Kirchmer, P.; Röttele, H.; Schröder, G. Angew. Chem. 1998, 110, 1954-1957.

doi:10.1002/(SICI)1521-3757(19980703)110:13/14<1954::AID-ANGE1 954>3.0.CO;2-U

Angew. Chem., Int. Ed. 1998, 37, 1854-1857.

doi:10.1002/(SICI)1521-3773(19980803)37:13/14<1854::AID-ANIE185 $4>3.0 . \mathrm{CO} ; 2-\mathrm{O}$

12. Kimball, D. B.; Herges, R.; Haley, M. M. J. Am. Chem. Soc. 2002, 124, 1572-1573. doi:10.1021/ja017227u

13. Kimball, D. B.; Weakley, T. J. R.; Herges, R.; Haley, M. M. J. Am. Chem. Soc. 2002, 124, 13463-13473. doi:10.1021/ja027809r

14. Shirtcliff, L. D.; Weakley, T. J. R.; Haley, M. M.; Köhler, F.; Herges, R. J. Org. Chem. 2004, 69, 6979-6985. doi:10.1021/jo049011r

15. Shirtcliff, L. D.; Hayes, A. G.; Haley, M. M.; Köhler, F.; Hess, K.; Herges, R. J. Am. Chem. Soc. 2006, 128, 9711-9721. doi:10.1021/ja054547v

16. Shirtcliff, L. D.; Haley, M. M.; Herges, R. J. Org. Chem. 2007, 72, 2411-2418. doi:10.1021/jo0622274

17. McClintock, S. P.; Shirtcliff, L. D.; Herges, R.; Haley, M. M. J. Org. Chem. 2008, 73, 8755-8762. doi:10.1021/jo801390x

18. McClintock, S. P.; Forster, N.; Herges, R.; Haley, M. M. J. Org. Chem. 2009, 74, 6631-6636. doi:10.1021/jo9011283

19. Young, B. S.; Köhler, F.; Herges, R.; Haley, M. M. J. Org. Chem. 2011, 76, 8483-8487. doi:10.1021/jo201378t

20. McClintock, S. P.; Zakharov, L. N.; Herges, R.; Haley, M. M. Chem.-Eur. J. 2011, 17, 6798-6806. doi:10.1002/chem.201002936

21. Young, B. S.; Herges, R.; Haley, M. M. J. Org. Chem. 2013, 78, 1977-1983. doi:10.1021/jo3020374
22. The rules do not apply to pseudocoarctate reactions. Similar to pseudopericyclic reactions, pseudocoarctate reactions do not exhibit a cyclic overlap of orbitals. In analogy to pseudopericyclic reactions which do not follow the Woodward-Hoffmann rules, pseudocoarctate reactions do not follow the above stereochemical, or thermal/photochemical selection rules.

23. Tseng, K. L.; Michl, J. J. Am. Chem. Soc. 1977, 99, 4840-4842. doi:10.1021/ja00456a059

24. Mahata, S.; Bhattacharya, S. K. Chem. Phys. Lett. 2009, 477, 52-56. doi:10.1016/j.cplett.2009.06.086

25. The amount of $\mathrm{CO}$ formed is larger than the sum of organic fragments listed. This is due to the fact that not all organic fragments could be assigned.

26. Arnold, B. R.; Balaji, V.; Michl, J. J. Am. Chem. Soc. 1990, 112, 1808-1812. doi:10.1021/ja00161a025

27. For entropic reasons, ring-closure of biradicals with formation of medium size rings is highly unfavourable at the temperature of pyrolysis.

28. Roth, W. R.; Biermann, M.; Dekker, H.; Jochems, R.; Mosselman, C.; Hermann, H. Chem. Ber. 1978, 111, 3892-3903. doi:10.1002/cber.19781111215

29. Chapman, O. L.; McMahon, R. J.; West, P. R. J. Am. Chem. Soc. 1984, 106, 7973-7974. doi:10.1021/ja00337a055

30. Lemal, D. M.; Gosselink, E. P.; McGregor, S. D. J. Am. Chem. Soc. 1966, 88, 582-600. doi:10.1021/ja00955a035

31. Davis, D.; Vysotskiy, V. P.; Sajeev, Y.; Cederbaum, L. S. Angew. Chem. 2012, 124, 8127-8131. doi:10.1002/ange.201204162 Angew. Chem., Int. Ed. 2012, 51, 8003-8007. doi:10.1002/anie.201204162

32. Herges, R.; Hoock, C. Science 1992, 255, 711-713. doi:10.1126/science.255.5045.711

33. Herges, R., Habilitationsschrift, University of Erlangen-Nuremberg, 1990.

34. Dunkin, I. Matrix Isolation Techniques: A Practical Approach; Oxford University Press: Oxford, U.K., 1998.

35. Birch, A. J.; Fitton, P.; Smith, D. C. C.; Steere, D. E.; Stelfox, A. R. J. Chem. Soc. 1963, 2209-2216. doi:10.1039/jr9630002209

\section{License and Terms}

This is an Open Access article under the terms of the Creative Commons Attribution License (http://creativecommons.org/licenses/by/2.0), which permits unrestricted use, distribution, and reproduction in any medium, provided the original work is properly cited.

The license is subject to the Beilstein Journal of Organic Chemistry terms and conditions: (http://www.beilstein-journals.org/bjoc)

The definitive version of this article is the electronic one which can be found at: doi:10.3762/bjoc.9.191 